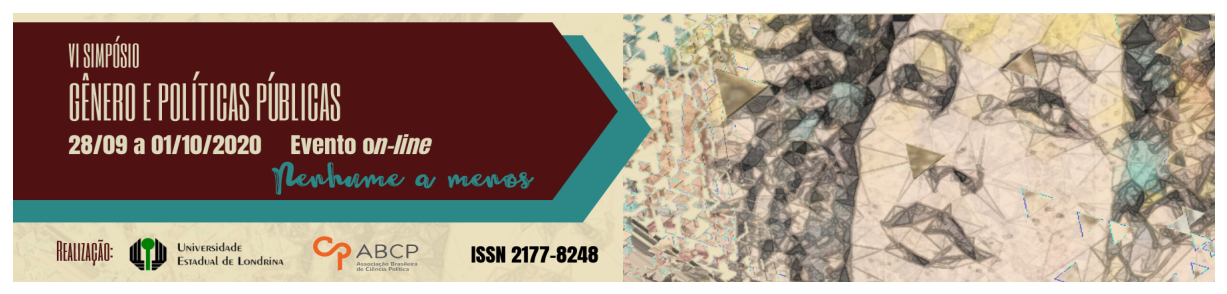

\title{
Quando gênero vira "ideologia": entendendo o discurso de negação dos direitos humanos de minorias socialmente excluídas
}

\author{
Lorena Betina Lazarini ${ }^{1}$; Marisse Costa de Queiroz ${ }^{2}$
}

\section{Resumo}

Esse analisa a influência de discursos conservadores que negam a existência e a efetivação, por meio da educação, de direitos humanos complexos, compreendidos na categoria dos direitos sexuais e dos direitos reprodutivos. $\mathrm{O}$ objetivo é fazer um levantamento das notícias divulgadas nos meios de comunicação e mídias sociais por organizações que utilizam o termo "ideologia de gênero" em seu discurso, a fim de descrever seus argumentos, fontes teóricas e fundamentos. Parte-se da concepção de que existe uma ordem de gênero, dirigido à normatização de comportamentos (CONNELL, 2015; BUTLER, 2012). Por meio de revisão da literatura e análise documental, os resultados da pesquisa apontam que os grupos que utilizam em seus discursos a expressão "ideologia de gênero" movimentam recursos materiais e simbólicos para legitimar uma concepção única e fechada de masculinidade e feminilidade, atacando direitos reconhecidos de grupos minoritários.

Palavras-chave: direitos humanos; gênero; ideologia.

\footnotetext{
1 Graduanda do Curso de Direito da Pontifícia Universidade Católica do Paraná Campus Londrina. Email: lorena_b.1@hotmail.com.

2 Mestra, professora no curso de Direito, orientadora do Projeto de Iniciação Científica (PIBIC) da Pontifícia Universidade Católica do Paraná, e-mail: marisse.queiroz@pucpr.br
}

GT 19 - Sexualidade, gênero e políticas educacionais 


\title{
When gender becomes "ideology": understanding the discourse of denying the human rights of socially excluded minorities
}

\begin{abstract}
This work seeks to analyze the influence of conservative discourses that deny the existence and the realization, through education, of complex human rights, included in the category of sexual and reproductive rights. The objective is to survey the news published in the media and social media by organizations that use the term "gender ideology" in their discourse, in order to describe their arguments, theoretical sources and foundations. It starts from the conception that there is an order of gender, directed to the standardization of behaviors (CONNELL, 2015; BUTLER, 2012). Through literature review and documentary research, the results of the research show that the groups that use the expression "gender ideology" in their speeches move material and symbolic resources to legitimize a unique and closed conception of masculinity and femininity, attacking recognized rights minority groups.
\end{abstract}

Keywords: human rights; gender; ideology.

\section{Introdução}

Nos últimos anos, as tentativas de se criar políticas públicas relacionadas à educação sobre gênero, sexualidade e demais assuntos conexos, vem sendo atacadas na esfera das instituições educacionais, para impedir o acesso a informação e às discussões relacionadas ao tema por crianças e adolescentes. Assuntos como educação sexual e de gênero vem sendo considerado temas perseguidos e criminalizados como abordagens pedagógicas sobre direitos humanos especiais.

Com base nisso, surge o questionamento: como esses discursos e posicionamentos políticos têm afetado os direitos à informação de pais e educadores e, consequentemente, a efetivação do direito fundamental à educação em relação a crianças e adolescentes? Analisar a influência de discursos relacionados à negação de direitos humanos complexos, compreendidos na categoria dos direitos sexuais e dos direitos reprodutivos é o foco central da pesquisa, concretizado por meio do levantamento das notícias divulgadas nos meios de comunicação e 
mídias por organizações que utilizam o termo "ideologia de gênero" em seu discurso, a fim de descrever seus argumentos, fontes teóricas e fundamentos.

A pesquisa foi realizada por meio da revisão bibliográficas e da análise de documentos com a abordagem descritiva e a discussão do problema feita de maneira qualitativa. Foram utilizados 4 critérios para seleção das Instituições que tiveram seus discursos analisados, considerando: a utilização da expressão "ideologia de gênero"; a organização; a abrangência e a manutenção de sites para veiculação dos discursos. A pesquisa resultou numa lista definitiva de 5 instituições que tiveram suas publicações analisadas.

Os dados coletados demostram que um dos argumentos utilizados nesses discursos contra os direitos sexuais seria de que eles estariam ligados a uma ideologia de gênero. $O$ objetivo principal da pesquisa é, a partir desse ponto de partida, descrever quais são os fundamentos de se denominar direitos humanos especiais como ideológicos, perigosos e lesivos.

Para descrever e analisar tal fenômeno, consideramos que gênero determina estruturas sociais multidimensionais relacionadas às identidades, aos modos de organização do trabalho, à sexualidade e aos regimes de poder e suas instituições que geram corporificações sociais especificas nos processos sociais de agência dos corpos ligados à arena reprodutiva na vida social (CONNELL; PEARSE, 2015). É também um fenômeno histórico-social tendente a normatizar comportamentos e conformar corpos generificados, ditando suas condições de existência a partir dessa agência (BUTLER, 2012). Assim, corpos generificados são produtos de práticas disciplinares definidas socialmente com grande poder de maximizar ou minimizar as diferenças biológicas entre os corpos.

Os estudos de gênero também influenciaram e contribuíram para delinear um campo teórico importante que definiu e categorizou 
os direitos sexuais e os direitos reprodutivos ${ }^{3}$. Mesmo sendo categorias de direitos humanos, os direitos sexuais e os direitos reprodutivos possuem especificidades que os colocam na classificação de $3^{\mathrm{a}}$ e $4^{\mathrm{a}}$ geração ${ }^{4}$. São direitos definidos no campo das subjetividades ou

${ }^{3}$ Esses direitos foram amplamente discutidos e passaram a figurar em documentos internacionais importantes, como o Plano de Ação da Conferência Mundial de População e Desenvolvimento realizado no Cairo em 1994 (ONU, 1994) 1994) e na Plataforma de Ação da IV Conferência Mundial da Mulher realizada em Pequim em 1995 (ONU, 1995). O primeiro documento, também denominado Plano de Ação do Cairo, trouxe uma nova perspectiva para os problemas demográficos, que passaram a ser discutidos como questões de direitos humanos, com ênfase no respeito aos direitos reprodutivos (VENTURA, 2003). A elaboração do documento foi totalmente marcada pelos estudos de gênero. Os direitos sexuais são definidos como a possibilidade de vivenciar uma vida sexual com prazer e livre de discriminação, sendo que sua efetividade está relacionado com a promoção de liberdades e garantias que incluem o direito de decidir livre e responsavelmente sobre sua sexualidade sem intervenções externas; o direito de ter controle sobre o próprio corpo; o direito de vivenciar livremente sua orientação sexual, sem sofrer violência, discriminação e coerção; o direito à privacidade; e o direito à saúde sexual, o qual exige o acesso a todo tipo de informação, educação e a serviços confidenciais de alta qualidade sobre sexualidade e saúde sexual, incluindo recursos tecnológicos quando necessários (PIOVESAN, 2003, p. 247). Os direitos reprodutivos compreendem o direito básico de todo casal e de todo indivíduo de decidir livre e responsavelmente sobre o número, o espaçamento e a oportunidade de ter filhos e de ter a informação e os meios de assim o fazer, gozando do mais elevado padrão de saúde sexual e reprodutiva. Incluem o direito: a) individual de mulheres e homens decidirem livre e responsavelmente o número de filhos e os intervalos entre eles; b) de tomar decisões sobre a reprodução, livre de discriminação, coerção ou violência; c) de homens e mulheres participarem com iguais responsabilidades na criação dos/as filhos/as; d) a serviços de saúde pública de qualidade e acessíveis, durante todas as etapas da vida. (PIOVESAN, 2003, p. 247).

4 Classificar os direitos humanos em gerações ou dimensões, fazem parte da teoria geracional desenvolvida por Karel Kasak em 1979. Segundo essa teoria os direitos humanos se desenvolvem em momentos históricos diversos, que vão se ampliando e complementando. Assim os direitos humanos de $1^{\mathrm{a}}$ geração estão relacionados às liberdades individuais, legado da revolução burguesa moderna, na qual o Estado não intervém na autonomia privada (obrigação de abstenção). A segunda geração diz respeito aos direitos sociais básicos, fundados no princípio da igualdade e que demandam prestações positivas do Estado. Os direitos de $3^{a}$ geração estão relacionados ao princípio da dignidade da pessoa humana e as garantias existenciais dos sujeitos, surgido após a $2^{\mathrm{a}}$ Guerra Mundial, relacionando a direitos e bens comuns à toda humanidade e da cooperação entre os povos. Apesar de controvertida, alguns autores apoiam a existência de uma $4^{\mathrm{a}}$ geração de direitos humanos, decorrente das conquistas da $3^{\mathrm{a}}$ dimensão, ela amplia essas três dimensões anteriores e inova na consolidação do direito de participação democrática (democracia direta), o direito ao pluralismo, o direito à bioética e aos limites da manipulação genética. Portanto, estão fundados na defesa da dignidade da pessoa humana contra intervenções abusivas de particulares ou do Estado, fundamenta a teoria dos novos direitos decorrentes dos avanços científicos, informacionais (internet) e novas demandas ambientais. 
individualidades de seus titulares, incluindo, principalmente, a possibilidade de tomar decisões (poder) e de ter acesso a recursos (políticas públicas) que apoiem essas decisões. Também devem ser analisados no contexto relacional dos indivíduos, considerando que a vivência da sexualidade nos corpos implica na existência desses corpos num universo socialmente e politicamente mediado (CORRÊA; PETCHESKY, 1996, p. 149). Por estar inserida no contexto da cultura, ou seja, por seu significado depender da mediação e valoração social, a sexualidade humana deve ser considerada também por seus mecanismos sociais que a constituem e a normalizam. Portanto, a vivência da sexualidade nos corpos individualizados tem uma dimensão histórica, social e política, ou seja, possui um caráter construído (SCHIOCCHET; 2007).

Direitos sexuais e direitos reprodutivos estão, portanto, intimamente relacionados ao direito fundamental à saúde, mas também possuem uma dimensão mais ampla, dentre elas o direito à informação e à educação sexual vista de forma positiva e abrangente. Por conseguinte, temas como sexualidade, saúde sexual, diversidade sexual, dentre outros, passaram a figurar nas políticas educacionais no Brasil como direitos subjetivos de crianças e adolescentes e como obrigação do Estado em promovê-los por meio da transmissão de saberes sobre esses temas. Essa formação é também fundamental para a democracia como sistema que promove a convivência a partir da diversidade e da pluralidade.

As perspectivas teóricas apresentadas aqui sobre os estudos de gênero e sua intersecção com direitos humanos complexos (direitos sexuais e direitos reprodutivos) são explicativas da abordagem dos autores da pesquisa e fundamentaram a análise dos documentos selecionados, que afirmam ser tal perspectiva um tipo de "ideologia" que causa danos as famílias e às crianças e adolescentes.

\section{Apeando os discursos: materiais e métodos}


A pesquisa em torno da análise de conteúdos dos discursos que utilizam a expressão "ideologia de gênero" para se referir de modo negativo aos estudos de gênero e suas repercussões, partiu da seleção de instituições que as veiculam. A seleção das instituições levou em conta os seguintes critérios: a) utilizam como base de seu discurso o termo "ideologia de gênero"; b) possuem organização institucional e jurídica; c) possuem atuação em âmbito nacional; e d) possuem sites oficiais para publicação e divulgação de seus discursos. Essa pesquisa resultou numa lista definitiva de 5 instituições, conforme descrito na tabela abaixo.

Tabela 1 - Lista de Instituições

\begin{tabular}{|l|l|l|}
\hline \multicolumn{1}{|c|}{ DENOMINAÇAO } & \multicolumn{1}{c|}{$\begin{array}{c}\text { NATUREZA } \\
\text { JURÍDICA }\end{array}$} & \multicolumn{1}{c|}{ LINK DO SITE } \\
\hline $\begin{array}{l}\text { Associação Nacional dos } \\
\text { Juristas Evangélicos } \\
\text { (ANAJURE) }\end{array}$ & Associação Privada & $\underline{\text { https://anajure.org.br/ }}$ \\
\hline Comunidade Canção Nova & $\begin{array}{l}\text { Organização } \\
\text { Religiosa }\end{array}$ & $\begin{array}{l}\text { https://comunidade.ca } \\
\text { ncaonova.com/ }\end{array}$ \\
\hline $\begin{array}{l}\text { Instituto Plínio Correia de } \\
\text { Oliveira (IPCO) }\end{array}$ & Associação Privada & $\underline{\text { https://ipco.org.br/ }}$ \\
\hline $\begin{array}{l}\text { Movimento Brasil Livre } \\
\text { (MBL) }\end{array}$ & Associação Privada & $\underline{\text { https://mbl.org.br/ }}$ \\
\hline Partido Social Liberal (PSL) & Partido Político & $\underline{\text { https://psl.org.br/ }}$ \\
\hline
\end{tabular}

Fonte: as autoras (2020)

Estando definida a fonte, passou-se à seleção dos documentos a serem analisados. A fim de definir claramente o objeto de análise, ficou determinado que seriam analisados discursos veiculados exclusivamente em documentos escritos imprimíveis. Portanto, excluiuse dessa pesquisa discursos presentes em áudios e vídeos. Optou-se também por selecionar os documentos veiculados no ano de 2019. Com base nesses documentos e artigos selecionados, separamos apenas 
aqueles que iam de encontro com o objetivo do trabalho e que, portanto, traziam em seu texto o termo "ideologia de gênero".

Em resumo, utilizando a técnica de análise de documentos, com a abordagem descritiva, selecionamos, após definição das instituições (Tabela 1), os documentos públicos divulgados em seus sites oficiais, que nessa segunda etapa resultou na seleção de 20 documentos, cuja busca se deu pelo termo "ideologia de gênero", publicados nos sites das Instituições.

Tabela 2 - Documentos selecionados que utilizam o termo "ideologia de gênero, publicados (as) no ano de 2019.

\begin{tabular}{|c|c|c|c|}
\hline ORDEM & TÍTULO & INSTITUIÇAO & TIPO \\
\hline DOC. 1 & $\begin{array}{l}\text { A homofobia, o STF, a religião e a } \\
\text { opinião de renomados cientistas }\end{array}$ & IPCO & Artigo \\
\hline DOC. 2 & $\begin{array}{l}\text { STF, Homofobia e a palavra-talismã } \\
\text { que assassina o senso moral }\end{array}$ & IPCO & Artigo \\
\hline DOC. 3 & $\begin{array}{l}\text { STF pode tornar crime defender a } \\
\text { Moral Católica }\end{array}$ & IPCO & Artigo \\
\hline DOC. 4 & $\begin{array}{l}\text { "Brian ou Brenda?": uma história } \\
\text { distorcida em prol da ideologia de } \\
\text { gênero }\end{array}$ & IPCO & Artigo \\
\hline DOC. 5 & $\begin{array}{l}\text { Meninos vestem azul, meninas } \\
\text { vestem rosa? }\end{array}$ & IPCO & Artigo \\
\hline DOC. 6 & $\begin{array}{l}\text { ANAJURE emite NOTA PÚBLICA } \\
\text { sobre a tese firmada no julgamento da } \\
\text { ADO 26, relativa à criminalização da } \\
\text { Homo/Transfobia }\end{array}$ & ANAJURE & $\begin{array}{l}\text { Nota } \\
\text { Pública }\end{array}$ \\
\hline DOC. 7 & $\begin{array}{l}\text { ANAJURE lança Nota Pública sobre } \\
\text { parecer da AGU acerca da ideologia } \\
\text { de gênero nas leis estaduais e } \\
\text { municipais }\end{array}$ & ANAJURE & $\begin{array}{l}\text { Nota } \\
\text { Pública }\end{array}$ \\
\hline DOC. 8 & $\begin{array}{l}\text { ANAJURE lança NOTA PÚBLICA em } \\
\text { apoio à suspensão de Vestibular }\end{array}$ & ANAJURE & $\begin{array}{l}\text { Nota } \\
\text { Pública }\end{array}$ \\
\hline
\end{tabular}




\begin{tabular}{|c|c|c|c|}
\hline & $\begin{array}{l}\text { destinado exclusivamente a } \\
\text { indivíduos transgêneros }\end{array}$ & & \\
\hline DOC. 9 & $\begin{array}{l}\text { ANAJURE emite Nota Pública sobre a } \\
\text { orientação do Governo brasileiro } \\
\text { sobre o uso do termo "Gênero" }\end{array}$ & ANAJURE & $\begin{array}{l}\text { Nota } \\
\text { Pública }\end{array}$ \\
\hline DOC. 10 & $\begin{array}{l}\text { ANAJURE emite Nota Pública } \\
\text { referente a Súmula do Conselho } \\
\text { Federal da OAB sobre violência } \\
\text { contra pessoas LGBTQI+ }\end{array}$ & ANAJURE & $\begin{array}{l}\text { Nota } \\
\text { Pública }\end{array}$ \\
\hline DOC.11 & $\begin{array}{l}\text { ANAJURE e entidades educacionais } \\
\text { parceiras emitem Nota Pública sobre } \\
\text { caso da escola Adventista que } \\
\text { englobou o tema da } \\
\text { homossexualidade em avaliação } \\
\text { escolar }\end{array}$ & ANAJURE & $\begin{array}{l}\text { Nota } \\
\text { Pública }\end{array}$ \\
\hline DOC. 12 & $\begin{array}{l}\text { Ideologia de gênero e a desconstrução } \\
\text { da família }\end{array}$ & Canção Nova & $\begin{array}{l}\text { Artigo } \\
\text { Público }\end{array}$ \\
\hline DOC. 13 & $\begin{array}{l}\text { Ideologia de gênero: as crianças me } \\
\text { inspiraram a escrever }\end{array}$ & Canção Nova & $\begin{array}{l}\text { Artigo } \\
\text { Público }\end{array}$ \\
\hline DOC. 14 & A hilária Ideologia de Gênero & Canção Nova & $\begin{array}{l}\text { Artigo } \\
\text { Público }\end{array}$ \\
\hline DOC. 15 & $\begin{array}{l}\text { Como lidar com o meu filho } \\
\text { homossexual? }\end{array}$ & Canção Nova & $\begin{array}{l}\text { Artigo } \\
\text { Público }\end{array}$ \\
\hline DOC. 16 & $\begin{array}{l}\text { Em Marcha para Jesus, Bolsonaro } \\
\text { afirma que ideologia de gênero é "do } \\
\text { capeta" }\end{array}$ & MBL & $\begin{array}{l}\text { Artigo } \\
\text { Público }\end{array}$ \\
\hline DOC. 17 & $\begin{array}{l}\text { O Escola Sem Partido morreu, mas } \\
\text { passa bem }\end{array}$ & MBL & $\begin{array}{l}\text { Artigo } \\
\text { Público }\end{array}$ \\
\hline DOC. 18 & $\begin{array}{l}\text { Resposta ao nojento artigo de Jean } \\
\text { Wyllys sobre Karol Eller }\end{array}$ & MBL & $\begin{array}{l}\text { Artigo } \\
\text { Público }\end{array}$ \\
\hline DOC. 19 & Em que acreditamos & PSL & $\begin{array}{l}\text { Artigo } \\
\text { Público }\end{array}$ \\
\hline DOC. 20 & Novo estatuto do PSL & PSL & $\begin{array}{l}\text { Artigo } \\
\text { Público }\end{array}$ \\
\hline
\end{tabular}

Fonte: As autoras (2020). 
Definido os documentos a serem analisados (Tabela 2), passouse ao mapeamento das linhas argumentativas presentes nos discursos ali materializados. Tendo por foco descrever como essas instituições explicam e fundamentam certos campos de conhecimento como ideológicos, mapeamos 4 linhas argumentativas explicativas de seus posicionamentos: a) argumentos com fundamentos religiosos; b) argumentos com fundamentos conservadores; c) argumentos com fundamentos políticos e históricos; e d) argumentos de cunho biologicista. A Tabela 3 resume essas linhas argumentativas e descreve seus desdobramentos.

Tabela 3 - Linhas argumentativas presentes nos documentos analisados explicativas do termo "ideologia de gênero"

\begin{tabular}{|c|c|}
\hline $\begin{array}{l}\text { LINHA } \\
\text { ARGUMENTATIVA }\end{array}$ & DESDOBRAMENTOS \\
\hline \multirow{3}{*}{$\begin{array}{l}\text { 1. Argumentos de } \\
\text { caráter religioso. }\end{array}$} & $\begin{array}{l}\text { Afirmações de que os estudos de gênero são ataques } \\
\text { contra as religiões cristãs. }\end{array}$ \\
\hline & $\begin{array}{l}\text { Os estudos de gênero impedem a transcendência e a } \\
\text { conexão com Deus. }\end{array}$ \\
\hline & $\begin{array}{l}\text { Nascer (biologicamente) homem ou mulher são } \\
\text { criações divinas inquestionáveis. }\end{array}$ \\
\hline \multirow{4}{*}{$\begin{array}{l}\text { 2. Argumentos } \\
\text { conservadores. }\end{array}$} & Estudos de gênero visam destruir a família. \\
\hline & $\begin{array}{l}\text { Educação sexual promovem a sexualização precoce } \\
\text { das crianças. }\end{array}$ \\
\hline & $\begin{array}{l}\text { Assumir sexualidades heterodiscordantes destrói a } \\
\text { identidade genuína dos sujeitos. }\end{array}$ \\
\hline & $\begin{array}{l}\text { O ensino e educação de crianças e adolescentes deve } \\
\text { estar em harmonia com as conviç̧ões religiosas dos } \\
\text { pais e familiares. }\end{array}$ \\
\hline \multirow[t]{2}{*}{$\begin{array}{l}\text { 3. Argumentos que } \\
\text { evocam fatos políticos } \\
\text { e históricos. }\end{array}$} & $\begin{array}{l}\text { Afirmações de que estudos de gênero tem, } \\
\text { necessariamente, relação com posições políticas de } \\
\text { esquerda. }\end{array}$ \\
\hline & $\begin{array}{l}\text { Afirmações de que estudos de gênero tem, } \\
\text { necessariamente, relação a teoria marxista. }\end{array}$ \\
\hline
\end{tabular}




\begin{tabular}{|l|l|}
\cline { 2 - 2 } & $\begin{array}{l}\text { Afirmações sobre a existência de um projeto político } \\
\text { totalitário que pretende impor comportamentos } \\
\text { homoafetivos. }\end{array}$ \\
\hline \multirow{4}{*}{$\begin{array}{l}\text { 4. Argumentos } \\
\text { biologicistas. }\end{array}$} & $\begin{array}{l}\text { Afirmações de que os estudos de gênero não } \\
\text { possuem cientificidade. }\end{array}$ \\
\cline { 2 - 2 } & $\begin{array}{l}\text { Simetria entre determinações biológicas e genéticas e } \\
\text { construções e valorações sociais sobre essas } \\
\text { características. }\end{array}$ \\
\cline { 2 - 2 } $\begin{array}{l}\text { Simetria da ideia jurídica de igualdade com as } \\
\text { diferenças biológicas e fenotípicas de homens e } \\
\text { mulheres. }\end{array}$ \\
\hline
\end{tabular}

Fonte: os autores (2020)

Numericamente os documentos que apresentaram essas linhas argumentativas e seus respectivos desdobramentos estão demonstrados na figura 1 abaixo:

Figura 1. Quantidade de documentos segundo a linha argumentativa mapeada

1. Argumentos de caráter religioso.

2. Argumentos conservadores.

3. Argumentos que evocam fatos políticos e históricos.

4. Argumentos biologicistas.

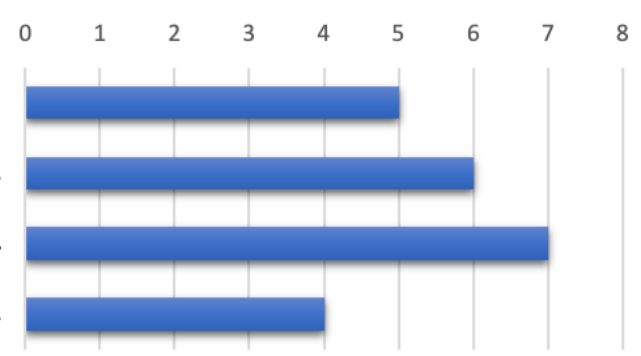

Fonte: as autoras (2020)

Consideramos como argumentos religiosos (primeira linha argumentativa) os discursos que fundamentam sua discordância com os estudos de gênero com base em cânones e dogmas religiosos. Essa linha argumentativa pode ser verificada em 5 documentos analisados (DOCs. 2, 3, 12, 13 e 14).

Por argumentos conservadores entendemos aqueles discursos fundados numa concepção restrita de sexualidade humana, de família e 
identidade de gênero de base exclusivamente heteronormativa ${ }^{5}$. Assim todos os comportamento ou composições familiares que destoam do modelo heterossexual, são consideradas erradas, pecaminosas ou patológicas. Essa linha argumentativa foi identificada em 6 documentos dos 20 analisados (DOCs. 1, 4, 5, 7, 12 e 19).

Os discursos dessas Instituições também apelam a teorias sociais, movimentos e organizações sociais e a fatos históricos e políticos para fundamentar seus argumentos. Essas referencias, em geral, possuem tom acusatório e deslegitimador das referencias citadas, sendo também argumentos usados para corroborar com as demais linhas argumentativas. Esse tipo de argumento foi encontrado 7 dentre os 20 documentos analisados (DOCs. 1, 2, 3, 5, 7, 14 e 16).

A última linha argumentativa mapeada faz uso de argumentos pretensamente científicos para refutar os estudos de gênero. Citam cientistas, médicos e juristas que se opõem aos estudos de gênero. Mas uma análise mais aprofundada do referencial utilizado, demonstra que são os estudos citados que não possuem cientificidade e pertencem a grupos de interesses formados em torno dos valores e ideologias que tais instituições advogam. Uma outra característica dessa linha argumentativa é distorcer os argumentos utilizados por teóricas e teóricos do campo dos estudos de gênero. Por exemplo, eles confundem a demanda dos movimentos feministas e LGBTQI+ por igualdade de direitos, como se fosse uma reivindicação de serem considerados

\footnotetext{
5 Termo que descreve situações nas quais orientações sexuais diferentes da heterossexual são marginalizadas, ignoradas ou perseguidas por práticas sociais, crenças ou políticas. Isto inclui a ideia de que os seres humanos são definidos sexualmente por duas categorias distintas e complementares: macho e fêmea. A partir dessa binariedade sexual rígida vai influenciar diversas outras crenças e normas, por exemplo, define que relações afetivo-sexuais (namoro e relações conjugais) são "normais" e aceitáveis somente entre pessoas de sexos diferentes; que cada sexo tem certos papéis e funções sociais inquestionáveis (p.ex., o mito do "instinto materno" e do "compulsão sexual" para os homens). Assim, sexo biológico, identidade de gênero, orientação sexual e papéis sociais deveriam enquadrar qualquer pessoa dentro de normas rígidas que podem ser explícitas ou implícitas. Aqueles que identificam e criticam a heteronormatividade dizem que ela distorce o discurso ao estigmatizar conceitos desviantes tanto de sexualidade quanto de gênero e tornam certos tipos de auto expressão mais difíceis de serem vivenciadas sem estigmas ou violências.
} 
biologicamente iguais. Verificamos esse tipo de argumentação em 4 documentos dos 20 analisados (DOCs. 1, 7, 9 e 13).

Alguns documentos analisados (DOCs. 6, 8, 9, 10, 11, 15, 17, $18 \mathrm{e}$ 20) não se encaixaram nas linhas argumentativas mapeadas na tabela 2. A tabela 3 foi desenvolvida com trechos selecionados dos documentos analisados a titulo de exemplificação da construção desses discursos.

Tabela 4 - Seleção de trechos dos discursos presentes nos documentos analisados, com intuito exemplificativo.

\begin{tabular}{|c|c|}
\hline \multicolumn{2}{|c|}{ 1. ARGUMENTOS DE CARÁTER RELIGIOSO } \\
\hline DOC. & TRECHO SELECIONADO \\
\hline 1 & $\begin{array}{l}\text { "Através de uma simples interpretação, a moral católica terá se } \\
\text { tornado inconstitucional, conforme a nefasta "Ideologia de } \\
\text { Gênero". }\end{array}$ \\
\hline 12 & $\begin{array}{l}\text { "O último dos itens dessa agenda é de caráter antimetafísico. } \\
\text { Qualquer tipo de relação com a transcendência, com a religião ou } \\
\text { com o ser Criador deve ser simplesmente anulada. }\end{array}$ \\
\hline 13 & $\begin{array}{l}\text { "A ideologia de gênero é um mal que declara guerra às diferenças } \\
\text { biológicas, destruindo assim a mais bela criação de Deus: o homem } \\
\text { e a mulher." }\end{array}$ \\
\hline \multicolumn{2}{|c|}{ 2. ARGUMENTOS CONSERVADORES. } \\
\hline DOC. & TRECHO SELECIONADO \\
\hline 1 & $\begin{array}{l}\text { "A primeira definição do termo ideologia de gênero é, então, } \\
\text { movimento que pretende desconstruir a família e os vínculos } \\
\text { existentes dentro dela. O próximo será a desconstrução do } \\
\text { significado do termo "pessoa" e até mesmo do termo "indivíduo"; } \\
\text { sendo assim, quem decide, no seu lugar, não é mais alguém } \\
\text { autônomo, mas alguém que poderia deixar nas mãos de outro essa } \\
\text { decisão. O passo seguinte seria o mais abrangente de todos: } \\
\text { eliminada a pessoa, eliminam-se suas relações e seus efeitos. }\end{array}$ \\
\hline 4 & $\begin{array}{l}\text { "John Money, iniciador da ideologia de gênero. Ao tentar por em } \\
\text { prática sua teoria destruiu a vida de uma família inteira." }\end{array}$ \\
\hline
\end{tabular}




\begin{tabular}{|c|c|}
\hline & $\begin{array}{l}\text { "A cirurgia para mudança de sexo não proporciona felicidade e } \\
\text { suas consequências são transtornos psicológicos que levam o } \\
\text { paciente ao suicídio." } \\
\text { "A ideologia de gênero mata a alma e destrói pessoas e lares." }\end{array}$ \\
\hline 5 & $\begin{array}{l}\text { Essa importante associação de pediatras dos Estados Unidos } \\
\text { declarou que a "ideologia de gênero é nociva às crianças" }\end{array}$ \\
\hline 7 & $\begin{array}{l}\text { "Os pais e, quando for o caso, os tutores, têm direito a que seus } \\
\text { filhos e pupilos recebam a educação religiosa e moral que esteja de } \\
\text { acordo com suas próprias convicções. Dessa forma, inserir } \\
\text { componentes curriculares ou simplesmente ideologias contrárias } \\
\text { ao que a criança recebe em casa pelos seus pais constitui um abuso } \\
\text { e uma ilegalidade." }\end{array}$ \\
\hline 12 & $\begin{array}{l}\text { "A ideologia de gênero pretende desconstruir a família e os } \\
\text { vínculos existentes dentro dela." }\end{array}$ \\
\hline 19 & "A ideologia de gênero causa a sexualização precoce das crianças" \\
\hline 7 & $\begin{array}{l}\text { "Negando o que se percebe na realidade cotidiana, segundo a } \\
\text { ideologia de gênero, as pessoas não nascem homens ou mulheres, } \\
\text { mas são elas próprias condicionadas a identificarem-se como } \\
\text { homens, como mulheres, ou como um ou mais dos diversos } \\
\text { gêneros que podem ser criados pelo indivíduo ou pela sociedade." }\end{array}$ \\
\hline \multicolumn{2}{|r|}{ 3. ARGUMENTOS QUE EVOCAM FATOS POLÍTICOS E HISTÓRICOS } \\
\hline DOC. & TRECHO SELECIONADO \\
\hline 1 & $\begin{array}{l}\text { "A criminalização da homofobia e da transfobia, trombeteada pela } \\
\text { mídia de esquerda, representa mais um passo na debilitação do } \\
\text { senso moral no Brasil." }\end{array}$ \\
\hline 7 & $\begin{array}{l}\text { "Na verdade, trata-se ela própria de uma mera construção social } \\
\text { hodierna, fruto das disputas e variações das idéias na história." }\end{array}$ \\
\hline 16 & $\begin{array}{l}\text { "A esquerda não se preocupa com a liberdade ou com os direitos } \\
\text { das minorias, a única coisa que importa é a agenda política e } \\
\text { ideológica." }\end{array}$ \\
\hline 14 & $\begin{array}{l}\text { "Ideologia de gênero tem sua nascente na ideologia marxista, mais } \\
\text { especificamente na obra 'A Origem da Família, da Propriedade } \\
\text { Privada e do Estado', de Friedrich Engels." }\end{array}$ \\
\hline
\end{tabular}




\begin{tabular}{|l|l|}
\hline 4. ARGUMENTOS BIOLOGICISTAS. \\
\hline 1 & $\begin{array}{l}\text { "A afirmação de que não se nasce mulher, torna-se mulher não tem } \\
\text { base científica." } \\
\text { "Homens e mulheres não podem ser tratados igualmente na } \\
\text { medicina porque apresentam diferenças genéticas." } \\
\text { "Devemos tratar nossos pacientes de acordo com sua biologia, não } \\
\text { de acordo com suas percepções ilusórias." }\end{array}$ \\
\hline $\begin{array}{l}\text { "Qualquer mínimo sinal de oposição aos componentes da teoria de } \\
\text { gênero, mesmo que fundado em alegações técnico-científicas, é } \\
\text { tratado não como uma decorrência da pluralidade de visões e da } \\
\text { liberdade de expressão, mas como uma manifestação a ser } \\
\text { silenciada por meio da associação distorcida ao que há de mais } \\
\text { abjeto na humanidade, e que certamente não é o alvo pretendido." } \\
\text { "Além disso, de modo velado, a teoria de gênero afasta critérios } \\
\text { claros decorrentes de aspectos biológicos que permeiam a conduta } \\
\text { de homens e mulheres para elevar a autonomia humana à condição } \\
\text { de dogma. O sexo com o qual se nasce é rejeitado; a influência da } \\
\text { sociedade, também, exceto quando é exercida para absorver os } \\
\text { ditames da teoria de gênero; subsiste, apenas, o próprio indivíduo } \\
\text { como autor de si." }\end{array}$ \\
\hline 13 & $\begin{array}{l}\text { “O objetivo, agora, é criar um ‘sistema educativo', pedagógico, } \\
\text { dentro do qual um dos passos seja permitir que a pessoa não se } \\
\text { sinta reconhecida na sua natureza. Essa suposta decisão vem } \\
\text { acompanhada de um aniquilamento da pessoa, substituindo-a por } \\
\text { alguém sem identidade". }\end{array}$ \\
\hline
\end{tabular}

Fonte: os autores (2020).

\section{Análise de conteúdo dos discursos: onde está a "ideologia"?}

Levando em consideração todo o material analisado, bem como os resultados obtidos, foi possível perceber que, dentre os discursos proferidos pelas instituições citadas, 4 linhas de argumentação se destacam. Um argumento recorrente é a visão de que os estudos de gênero são pensados para contrariar a chamada "moral católica com o intuito de desconstruir a família e os vínculos existentes dentro dela. Essas afirmações, veiculadas em tom acusatório e difamador, creditam 
que se trata de uma doutrinação dividida em fases, em que primeiro se tenta desconstruir a família, depois o significado de "pessoa" e de "indivíduo", sendo que as decisões do indivíduo não mais serão feitas por ele e sim por uma terceira pessoa. Para as instituições que se utilizam desses argumentos, o próximo passo seria eliminar as relações entre as pessoas e seus efeitos e, por último, o dogma e as crenças cristãs.

Em oposição a essas ideias é importante esclarecer que os estudos de gênero não atacam a família, mas ao contrário defendem o reconhecimento de diversos tipos de família (pluralidade) que devem ser reconhecidas juridicamente para acessar direitos fundamentais. A política com perspectiva de gênero é, portanto, inclusiva e visa abarcar todos os tipos de família, e não destruir ou excluir a família tradicional. $\mathrm{O}$ intuito é apenas expandir esse conceito para englobar famílias que ainda hoje, não são entendidas como tal.

Em relação à afirmação de que busca-se destruir o significado de pessoa e de indivíduo, os estudos de gênero demonstram o contrário. A demonstração de a sexualidade e a subjetividade humana é complexa e diversa, serve para fundamentar a autonomia dos indivíduos em relação a seu corpo, vínculos afetivos e exercício da sexualidade e identidade.

Como já explicado o direito à educação sexual é um aspecto do desenvolvimento dos direitos sexuais e reprodutivos. A aprendizagem adequada e adaptada ao contexto cultural e à fase etária dos sujeitos sobre aspectos da sexualidade e reprodução humana, ao contrário de "sexualizar" precocemente as crianças, tem importante papel em seu desenvolvimento. Esse tipo de discussão ajuda as crianças a entender seus corpos, sua sexualidade, a respeitar a sexualidade de outras pessoas e a entender sobre o que pode ou não ser feito com elas. Muitos casos de abusos que ocorrem dentro da residência da criança, só são descobertos quando a educação sexual passa a ser um tema abordado dentro da escola. Ao invés de atrapalhar a criança, a educação abre seus olhos e a ajuda a identificar situações que não deveriam ocorrer. Além 
disso, evitam e previnem problemas que afetam grande parte da população e são considerados questões de saúde pública, tais como gravidez na adolescência ou gravidez indesejada, infecção por DSTs, violência sexual, violência doméstica, abortamento inseguro, etc.

Discussões que envolvem orientações sexuais não normativas ou envolvem temas identidades de gênero não binárias (transgêneras) são alvo constante desses discursos. Sobre a alegação de que as cirurgias de mudança de sexo não proporcionam felicidade ao indivíduo e causam transtornos psicológicos que podem levar o paciente ao suicídio, podemos afirmar o contrário. O que causa transtornos psicológicos e até o suicídio é a imposição de que o indivíduo deve "morar" no corpo em que nasceu, mesmo que não se identifique com ele, ou que deva se comportar de modo a obedecer a ideia que sociedade tem do que é certo. Não há transtorno psicológico maior que o causado pelo sentimento de não pertencer, de apresentar um corpo masculino quando sua cabeça e essência são femininas e vice e versa. A cirurgia de mudança de sexo visa apenas "corrigir" e adequar o corpo do indivíduo ao modo como ele se identifica. Essas técnicas são baseadas em estudos sérios e evidencias cientificas longamente testadas.

A terceira linha de argumentação, muito comum na sociedade contemporânea, é aquela que baseia seus argumentos em eventos específicos ou a partidos e posicionamentos políticos, como sendo uma verdade absoluta. Para quem profere esses discursos, a identidade de gênero é uma pauta que interessa somente à esquerda. Afirmações como que a criminalização da homofobia e transfobia são assuntos de interesse da "mídia esquerdista", deixam claro esse entendimento.

É certo que os partidos de esquerda apresentam grande preocupação em relação aos direitos das minorias e que, dentre essas minorias, estejam pessoas LGBTQI+, mulheres, negros, indígenas, deficientes, etc. Mas essas questões não estão relacionadas exclusivamente a partidos ou grupos de esquerda e suas pautas compõem diversas orientações políticas liberais, por exemplo. Muitas 
dessas organizações sequer possuem orientação política definida, auto intitulando-se organizações suprapartidárias, outros ainda estão vinculados a grupos religiosos de denominações diversas, inclusive cristās. Portanto, discussões de gênero, demandas por igualdade de direitos e reconhecimento, não é projeto político um único segmento, como os documentos analisados afirmam.

A última linha de argumentação que se destaca, é aquela com fundamento em ideias criacionistas e "biológicas". Esses discursos visam deslegitimar as teorias de gênero, afirmando que não possuem base científica. São argumentos reproduzidos por pessoas que defendem que só exista o conceito de homem e mulher e que estes não podem ser tratados igualmente por apresentarem diferenças genéticas/biológicas. Enxergam a identidade de gênero unicamente pelo critério das diferenças biológicas, como algo concreto e inquestionável. Afirmam que a identidade de gênero é justificada por conta de uma distorção dos fatos e por histórias em que se misturam fatos com ficção. Trata-se apenas de um modo de enxergar as coisas, sendo que esse modo, se baseia na ideia de que se pode comprovar que existem diferenças entre o corpo masculino e o feminino, desconsiderando que tampouco seu pressuposto é real, considerando que existe uma infinidade de seres humanos que nascem com características genéticas indefinida em relação ao sexo, como os intersexuais.

Fica claro também que, embora os argumentos tenham sido distribuídos em tabelas de acordo com o fundamento com o qual melhor se adequam, em vários dos discursos acima citados, há a existência de dois ou mais tipos de fundamentos diferentes na mesma sentença, que mistura argumentos com base em fundamentos políticos, ao dizer que a identidade de gênero é de esquerda, e argumentos com fundamentos criacionistas/biológicos ao se referir ao gênero como um ideologia, como se a identidade de gênero fosse algum tipo de ideia abstrata ou na corrente filosófica e não algo concreto. Fica claro, portanto que, embora proferidos por diferentes instituições e com base em diferentes 
fundamentos, os discursos contra a identidade de gênero estão em toda parte e, inclusive, pode-se identificar diferentes situações em que tais instituições, embora tenham princípios ou objetivos totalmente distintos, passam a se unir para combater determinado assunto, como é o que acontece neste caso.

\section{Considerações finais}

O objetivo deste trabalho foi fazer um levantamento das notícias divulgadas nos meios de comunicação e mídias por grupos ou organizações que utilizam o termo "ideologia de gênero" em seu discurso, a fim de descrever seus argumentos, fontes teóricas e fundamentos.

Cumpridas todas as etapas, listadas as instituições, seus discursos, seus argumentos e fundamentos, pudemos perceber que, embora grande parte da população esteja lutando em defesa da identidade de gênero, muitas pessoas, instituições e correntes ideológicas estão se usando de argumentos absurdos e da falta de informação das pessoas para combatê-la.

Isso causa um efeito imediato na sociedade, principalmente no que diz respeito à efetivação do direito à educação sexual, tanto de um modo geral, quanto em instituições específicas como as escolas. Isso porque, até o presente momento, essas instituições têm apresentado um grande poder de influência em nossa sociedade, principalmente no sentido de combater qualquer projeto que vise implementar a temática no rol de políticas públicas do Brasil.

Deste modo, faz-se extremamente necessária a confecção de pesquisas como esta, no intuito de levar informação à população e esclarecer possíveis dúvidas sobre o assunto para que, cada vez mais, essa temática seja citada e abordada em nosso país. 


\section{Referências}

ALTMANN, Helena. Orientação sexual nos parâmetros curriculares nacionais. Revista Estudos Feministas, ano 9, p. 575-585, 2001. Disponível em: http://www.scielo.br/pdf/ref/v9n2/8641.pdf/\%3E\%20Acesso.

BUTLER, Judith. Problemas de gênero. Feminismo e subversão de identidade. Tradução de Renato Aguiar. 4. ed. Rio de Janeiro: Civilização Brasileira, 2012.

CONNELL, Raewyn; PEARSE, Rebecca. Gênero: uma perspectiva global. 5. Ed. São Paulo: nVersos, 2015.

CORREA ROSA, Crishna Mirella de Andrade; BOLJEVAC CSUCSULY, Maria Juliana. Sexualidade de normatização: apontamentos sobre o discurso normativo e judiciário sobre o sexo e o gênero. Disponível em:

<http:/ / www.publicadireito.com.br/artigos/?cod=6b1a864b240fc77 e>

CORREA, Sonia; PETCHESKY, Rosalind. Direitos sexuais e reprodutivos: uma perspectiva feminista. Physis, Rio de Janeiro, v. 6, n. 1-2, p. 147-177, 1996. Disponível em: <http:/ / www.scielo.br/scielo.php?script=sci_arttext\&pid=S010373311996000100008\&lng=en\&nrm=iso>. Acesso em: 15 set. 2018.

DA COSTA OLIVEIRA, Assis. Desafios para a garantia dos direitos sexuais de crianças e adolescentes. Diplematique, 11 jun. 2018. Disponível em: <https://diplomatique.org.br/desafios-para-agarantia-dos-direitos-sexuais-de-criancas-e-adolescentes $/>$.

DAVIS MATTAR, Laura. Reconhecimento jurídico dos direitos sexuais - uma análise comparativa com os direitos reprodutivos. Sur. Revista Internacional de Direitos Humanos, n. 5, v. 8, p. 60-83, 2008. Disponível em:

<http:/ / www.scielo.br/scielo.php?script=sci_arttext\&pid=S180664452008000100004>.

LEITE, Vanessa. A sexualidade adolescente a partir de percepções de formuladores de políticas públicas: refletindo o ideário dos adolescentes sujeitos de direitos. Psic. Clin., Rio de Janeiro, v. 24, n. 1, 
p. $\quad$ 89-103, 2012. Disponível em: <http:/ / www.scielo.br/pdf/pc/v24n1/07.pdf>.

ONU. Declaração e Plataforma de Ação da IV Conferência Mundial Sobre a Mulher. Pequim, $1995 . \quad$ Disponível em: <http:/ / www.onumulheres.org.br/wpcontent/uploads/2014/02/declaracao_pequim.pdf>. Acesso em: 15 set. 2018.

ONU. Plataforma do Cairo: Relatório da Conferência Internacional sobre População e Desenvolvimento. Cairo, 1994. Disponível em: <http://www.unfpa.org.br/Arquivos/relatorio-cairo.pdf>. Acesso em: 15 set. 2018.

PIOVESAN, Flavia. Temas de Direitos Humanos. São Paulo: Max Limonad, 2003.

SCHIOCCHET, T. Marcos normativos dos direitos sexuais: uma perspectiva emancipatoria. In: BRAUNER, Maria Claudia Crespo. (Org.). Biodireito e gênero. Ijui: Unijui, 2007. p. 61-106. Disponível em: <https://unisinos.academia.edu/TaysaSchiocchet>. Acesso em: 15 set. 2018.

VENTURA, Miriam (org.). Direitos Sexuais e direitos reprodutivos na perspectiva dos direitos humanos: síntese par gestores, legisladores e operadores do direito. Rio de Janeiro: ADVOCACI, 2003. 